\title{
REVOLUCIONÁRIO E GAY: IDENTIDADES INCONCILIÁVEIS? ENTREVISTA COM JAMES GREEN
}

\author{
REVOLUCIONARIO Y GAY: ¿ IDENTIDADES INCONCILIABLES? \\ ENTREVISTA CON JAMES GREEN \\ REVOLUTIONARY AND GAY: INCONCILIABLE IDENTITIES? \\ INTERVIEW WITH JAMES GREEN
}

\author{
James Green ${ }^{1}$, Andréa Moreira Lima² e Frederico Viana Machado ${ }^{3}$ \\ ${ }^{1}$ Brown University, Providence/RI, United States \\ ${ }^{2}$ Centro Universitário UNA, Belo Horizonte/MG, Brasil \\ ${ }^{3}$ Universidade Federal do Rio Grande do Sul, Porto Alegre/RS, Brasil
}

James Naylor Green é um historiador brasilianista, militante e pesquisador de referência nos Estados Unidos e no Brasil devido ao seu ativismo na área LGBT e suas inúmeras pesquisas e publicações sobre a história latino-americana. Se formou em Ciência Política no Earlham College, em 1972, e cursou seu doutorado entre 1992 e 1996, na Universidade da Califórnia.

Green é professor de história na Universidade de Brown, onde possui um núcleo de pesquisa sobre sexualidade e as ditaduras civis e militares, com foco no Brasil. Atualmente, é diretor da Brown's Brazil Initiative e do Opening the Archives Project, além de diretor executivo da Brazilian Studies Association. Ainda, é professor visitante de diversas universidades, tais como as Princeton, Columbia e a Hebrew University of Jerusalem.

Foi um dos fundadores do movimento homossexual organizado no Brasil, no pioneiro Somos: Grupo de Afirmação Homossexual. O historiador chegou a passeio no Brasil em 1976, se identificou com o país e suas lutas sociais progressistas e por aqui permaneceu durante seis anos, se engajando nos movimentos sociais e nas produções acadêmicas de sua área. Atualmente, reside nos EUA mas retorna ao Brasil regularmente para dar continuidade aos seus trabalhos. Entre eles, tem destaque a sua contribuição como um dos responsáveis pelo capítulo de homossexualidade do relatório da Comissão Nacional da Verdade.

O americano, conhecido por seus amigos no Brasil como Jimmy, é autor de obras de destaque sobre homossexualidade e ditadura militar, tais como: "Além do Carnaval: a homossexualidade masculina no Brasil do século XX' (Green, 1999, 2000), livro derivado de sua tese de doutorado, orientada por José Carlos Moya; Homossexualismo em São Paulo e outros escritos (Green \& Trindade, 2005); "Frescos Trópicos: fontes sobre a homossexualidade masculina no Brasil - 1870 a 1980 (Green \& Políto, 2004); "Apesar de vocês: a oposição e a ditadura militar brasileira nos EUA" (Green, 2009); "Ditadura e homossexualidade no Brasil: repressão, resistência e busca da verdade" (Green \& Quinalha, 2014), dentre outras. Recentemente, lançou pela editora Civilização Brasileira o livro "Revolucionário e Gay: a vida extraordinária de Herbert Daniel - Pioneiro na luta pela democracia, diversidade e inclusão" (Green, 2018), resultado de dez anos de pesquisas sobre a história do ativista gay e guerrilheiro Herbert Daniel, morto em 1992. 
Herbert foi um dos pioneiros do movimento LGBT no Brasil e ativista pela democracia durante a ditadura militar. De certa forma, como o livro nos conta, a história política de Herbert Daniel se aproxima da história do próprio autor, o que torna a biografia ainda mais instigante, por apontar partes de vivências que se cruzam, mesmo que em tempos diferentes (Green, 2018).

James Green tem uma relevante produção acadêmica, com diversos artigos e capítulos de livro publicados; coleciona prêmios acadêmicos e de direitos humanos, o que reforça seu papel de intelectual engajado, lapidado desde o início de sua trajetória. Nesta entrevista abordamos temas centrais de seu último livro, como, por exemplo, o conceito de "Masculinidade Revolucionária”, "Biografia Recuperativa”, bem como das pesquisas e ativismos do autor e seus possíveis diálogos com conceitos importantes da Psicologia Social e Psicologia Política, tais como identidade e interseccionalidade. Além disso, buscamos refletir acerca do contexto político brasileiro contemporâneo e seus impactos nos direitos humanos e nas interseccionalidades entre gênero, sexualidade, raça, classe e outros marcadores sociais.

\section{***⿻丷木大}

1- Jimmy, gostaríamos de começar perguntando sobre seu contexto de trabalho hoje. Como evoluíram suas motivações para viver no Brasil no passado e permanecer até os dias atuais desenvolvendo trabalhos acadêmicos e de militância no país?

Os seis anos que vivi no Brasil talvez tenham sido os melhores anos da minha vida. Eu era jovem, idealista, aprendendo sobre uma nova cultura e participando na oposição ao regime militar e ao mesmo tempo liderando a ala esquerda do movimento LGBT, que na época chamamos de Movimento Homossexual.

Voltei para os Estados Unidos em 1982 e continuei a fazer trabalho político em Los Angeles, entre trabalhadores imigrantes mexicanos e centro-americanos e como ativista sindical, enquanto trabalhava como assistente social. Eu estava ganhando um salário médio e só tinha duas ou três semanas por ano para férias e realmente não tinha dinheiro para voltar ao Brasil.

Depois, várias pessoas me incentivaram a fazer um mestrado em Estudos LatinoAmericanos e continuar com um doutorado como forma de trabalhar no Brasil e me reconectar ao país.

Quando voltei, depois de 12 anos de ausência, fiquei com medo de não me adaptar às mudanças no Brasil. No entanto, eu não apenas encontrei, como ainda me relacionava bem com meus velhos amigos, mas entrei em um novo mundo acadêmico onde fiz novas amizades.

No entanto, minha intenção foi transformar meu trabalho como historiador em uma arena política, no primeiro momento escrevendo a história social da homossexualidade masculina no Rio de Janeiro e em São Paulo, algo que não existia. A partir de então, todos os meus trabalhos tiveram um significado acadêmico e político. 
2-Em seu último livro, "Revolucionário e gay: a extraordinária vida de Herbert Daniel", você reconstitui a trajetória biográfica de Herbert Daniel, apresentando-o como alguém que não pode ser esquecido pelo Brasil. Como você sintetizaria a importância política de Herbert para o nosso país?

Herbert foi um revolucionário em todos os significados dessa palavra. Primeiro, ele decidiu entrar na resistência radical ao regime militar ao se juntar a uma organização clandestina enquanto era estudante de medicina na Universidade Federal de Minas Gerais. Isso significava sacrificar sua vida sexual e emocional para se juntar a um movimento revolucionário que na época não oferecia espaço para os membros que eram gays.

Enquanto revolucionário, dedicou-se inteiramente à causa, inclusive participando do sequestro dos embaixadores da Alemanha e da Suíça para forçar o regime militar a libertar 110 presos políticos em troca da liberdade dos embaixadores.

Ele conseguiu permanecer na clandestinidade e evitar ser preso de janeiro de 1969 a setembro de 1974, quando deixou o país para o exílio europeu. Lá ele se refez. Começou a aceitar sua homossexualidade e desenvolveu um relacionamento de longo prazo com Cláudio Mesquita, que permaneceu ao seu lado por vinte anos. Enquanto estava no exílio parisiense e novamente quando retornou ao Brasil, ele exigiu que a esquerda repensasse suas ideias sobre homossexualidade, gênero, meio ambiente e outras questões.

Finalmente, quando descobriu que tinha a $A I D S$, mais uma vez, ele se refez e tornou-se um importante ativista da $A I D S$, inventando um novo discurso radical sobre a doença, que foi muito importante no Brasil e no exterior. Ele era uma pessoa notável cuja história de vida precisava ser reintroduzida para brasileiros que não o conheciam.

3-Apesar de todo trabalho realizado por Herbert Daniel na militância contra ditadura militar e, posteriormente, nas campanhas politicas em prol do combate a AIDS e das lutas ambientais, você ressalta no livro a pouca lembrança na sociedade sobre sua relevância, o que te levou a produzir esse livro a partir de uma metodologia de "biografia recuperativa". Fale-nos um pouco sobre essa metodologia e sua importância nessa pesquisa. Você acredita que esse esquecimento histórico e social sobre quem foi Herbert tenha relação com o preconceito devido a sua homossexualidade?

Quando Herbert vivia exilado em Paris, escreveu seu primeiro livro, "Passagens para o próximo sonho", que contava a história de sua vida clandestina e suas críticas à esquerda armada. Ele também descreveu em detalhes suas experiências trabalhando em uma sauna gay em Paris.

O livro é vivo e barroco em estilo e um pouco inacessível para a pessoa que procurava uma conta simples sobre a geração que pegou em armas contra o regime militar e depois contou suas aventuras revolucionárias. Quando retornou ao Rio, no final de 1981, a popularidade das memórias sobre a luta armada havia diminuído e, assim, seu livro só tinha uma edição. Além disso, acho que as seções do livro sobre homossexualidade e seu trabalho em uma sauna gay devem ter confundido ou alienado esquerdistas heterossexuais ou pessoas interessadas em ler sobre esse período que não entendiam bem a escrita de um homem gay que também era um revolucionário. Embora tenha publicado outros quatro livros e produzido uma peça original, nunca conseguiu se tornar um autor popular. E quando ele morreu em 1992, acho que a lembrança de sua vida desapareceu com sua morte. 
4- Como Herbert Daniel lidou, dentro e fora da luta armada, com os estereótipos que envolvem ser, ao mesmo tempo, gay e guerrilheiro?

Como Herbert admitiu em seus escritos, quando decidiu se juntar à organização revolucionária, sentiu que precisava reprimir sua homossexualidade e, assim, viveu quatro anos em uma agonia frustrada. Ele se apaixonaria por companheiros, mas não poderia fazer nada a respeito. A única outra pessoa na organização que ele suspeitava ser também gay não gostava dele, nem Herbert gostava da outra pessoa. Era como se ambos temessem que o outro revelasse seu segredo.

Assim, Herbert, para pertencer, teve que se adaptar às normas de comportamento, que eu chamo de masculinidade revolucionária, que exigiam um certo tipo de comportamento de homens (e mulheres) que haviam se juntado à luta armada. Eles tinham que ser frios, racionais, machistas, decisivos, sem emoções ou preocupações por suas vidas pessoais. A revolução foi tudo.

Se uma pessoa estava preocupada com sua sexualidade, isso era considerado uma fixação ou desvio pequeno-burguês e era desencorajado ou criticado. É claro que havia um standard duplo, já que homens e mulheres heterossexuais podiam discutir sua solidão, seu desejo de ter um parceiro ou mesmo flertar ou fazer sexo com outra camarada sem causar angústia.

De acordo com seus companheiros na organização, Daniel não se encaixava bem nesses padrões, mas era muito inteligente, o que lhe permitia compensar sua incapacidade de viver de acordo com os padrões da masculinidade revolucionária.

5- Para a Psicologia Social e, especificamente, a Psicologia Política, o conceito de identidade é uma categoria de análise fundamental para pensar a relação indivíduo e sociedade. No livro, você afirma que Herbert Daniel era uma figura complexa e tinha uma dupla clandestinidade, pois carregou na sua trajetória duas identidades aparentemente inconciliáveis: a de gay e a de revolucionário. Quais foram, naquele contexto, os motivos que tornaram essas duas características inconciliáveis?

É claro que não são inconciliáveis, mas a esquerda revolucionária dos anos 1960 e início dos anos 1970, assim entendia. A homossexualidade foi considerada com uma perversão moral ou uma fraqueza de personalidade. Os homossexuais eram considerados instáveis, fracos, vaidosos e incapazes de realizar tarefas perigosas. Muitos revolucionários pensavam que a homossexualidade era uma doença ou um produto da decadência capitalista que desapareceria com o estabelecimento de uma sociedade socialista ou comunista. Muitos membros da esquerda simplesmente aceitavam ideias católicas tradicionais sobre a homossexualidade. Eles eram capazes de criticar a moralidade da igreja sobre o sexo pré-marital, mas não sobre a homossexualidade.

É claro que havia exceções e dentro das organizações às quais Herbert pertencia havia algumas pessoas - a maioria mulheres - que aceitavam sua homossexualidade. No entanto, o clima da época e o domínio de uma cultura masculinista com rígidas noções de gênero, criaram um ambiente que excluía a possibilidade de um homossexual aberto ser membro da organização. É por isso que ele sentiu que precisava reprimir sua homossexualidade para se tornar um membro e permanecer dentro das organizações às quais ele acabou se juntando. 
6- Você argumentou que alguns pontos de encontro entre a história de Herbert Daniel e a sua motivaram a escrita deste livro. Poderia nos descrever em quais aspectos você se identifica com o Herbert Daniel? Como esta questão metodológica é tratada por você? Não apenas no caso desta pesquisa, mas com seu envolvimento afetivo e ideológico com os temas que estuda.

De muitas maneiras me identifiquei com Herbert, e é por isso que decidi escrever um livro sobre ele. Também fui apanhado na onda de entusiasmo em torno dos movimentos revolucionários na América Latina nos anos 60, que prometiam acabar com a desigualdade social e econômica e eliminar a pobreza, a exploração e a desumanização.

Meu trabalho político nos Estados Unidos antes de viajar para América Latina em 1976 foi muito mais relacionado à participação no trabalho de solidariedade com o Brasil, em 1973, nas campanhas contra a tortura e a repressão, e depois do golpe militar no Chile, em atividades denunciando o envolvimento do governo dos EUA na derrubada do governo socialista de Salvador Allende.

Quando comecei a fazer trabalho político no Brasil, em 1977, a luta armada já havia sido derrotada e o movimento estudantil e, depois, o movimento lésbico e gay, estavam envolvidos em atividades legais para mudar a sociedade no contex to de um país que estava se democratizando. No entanto, acho que temos uma energia semelhante. Nós dois amamos teatro - eu era ator quando jovem e ele dirigia teatro enquanto estava na universidade e depois quando voltou do exílio. Nós também amávamos ler em nossa juventude e gostávamos de escrever.

Mais importante, de maneiras diferentes, nós dois desafiamos a homofobia da esquerda e insistimos que ela mudasse à medida que ambos nos considerássemos parte da esquerda. Honestamente, eu realmente não sei se teríamos nos dado bem se nos conhecêssemos. A única maneira de manter distância da pessoa ou processo sobre o qual você está escrevendo é estar consciente de que você tem uma identificação subjetiva e pensar sobre as maneiras pelas quais você pode ser tendencioso no que você está pesquisando ou escrevendo. A maioria dos historiadores tem alguma conexão com seu trabalho que é subjetivo e influencia seu pensamento. Eu não acho que exista uma maneira simples de superar ou lidar com essa questão além de estar consciente dela como um problema.

7- Herbert Daniel foi candidato a deputado, tentou a via eleitoral como estratégia para atuação política, assim como toda uma geração pós-redemocratização. Inclusive, recentemente você o comparou a Jean Wyllys, entre outras coisas, por ambos serem homossexuais assumidos. Alguns anos atrás tivemos a figura do Clodovil na câmara dos deputados, que era assumido, mas cujas ideias não representavam os anseios e as pautas dos movimentos LGBT. Como você discutiria a relação entre a presença de homossexuais e outras identidades nos espaços de poder, e a coerência destas identidades com ideias que defendam seus direitos e especificidades?

Clodovil foi assumido, mas ele não era político sobre a sua homossexualidade. Ele, como muitos homens de sua geração, encontrou certa aceitação social dentro de um estereótipo de um homem afeminado que se importava com estilo, cultura e moda. Ele não se levantou contra a discriminação e a homofobia, mesmo quando, durante a ditadura, os censores quiseram cancelar seu programa porque ele era muito feminino e aparentemente gay quando os militares queriam tornar a homossexualidade invisível na televisão. 
Jean Wyllys, por outro lado, representa uma geração de pessoas nascidas após o fim da ditadura ou em seu crepúsculo que tiveram uma atitude muito diferente em relação à sua sexualidade. Como quase todos os outros jovens, a princípio foi muito difícil aceitá-lo, mas depois ele percebeu que declarar publicamente sua homossexualidade era um ato político. E no Congresso ele era um defensor consistente do movimento LGBT e suas demandas.

Eu o comparo com Herbert Daniel porque cada um, em seu próprio momento e à sua própria maneira, estava na vanguarda da mudança social em relação a ideias e preconceitos contra a homossexualidade e ambos tiveram a coragem de confrontar a sociedade, especialmente os elementos conservadores dentro dela.

8 - Além do trabalho político mais amplo, Herbert Daniel foi um grande ativista nas primeiras campanhas contra a AIDS. Sabemos que esta pauta ficou, durante muitos anos, restrita ao campo da saúde, via políticas de apoio e prevenção. É possível afirmar que o trabalho por ele desenvolvido contribuiu para o rompimento com o estigma da AIDS como "peste gay" e para a ampliação dos discursos para a legitimidade pública da homossexualidade?

Totalmente. Herbert Daniel escreveu o primeiro ensaio importante sobre a $A I D S$ em 1983, como um apêndice de um livro sobre a homossexualidade. Ele já estava explicando como a sociedade, a mídia e a profissão médica estavam estigmatizando as pessoas com o vírus e apontou todas as principais políticas que precisavam ser implementadas para derrotar o preconceito contra as pessoas vivendo com HIV/AIDS. Após a campanha eleitoral de 1986, Herbert consegue um emprego na Associação Brasileira Interdisciplinar de $A I D S$ (ABIA) no Rio de Janeiro, publicando seu boletim informativo e outros materiais nos quais expôs um conjunto claro e consistente de princípios para lutar contra a indiferença e a inação do governo. Mais tarde, ele foi reconhecido por seu trabalho pioneiro pelo Dr. Jonathan Mann, na época o maior especialista mundial em luta contra a $A I D S$, que dedicou seu livro de 1000 páginas "Global $A I D S$ " a Herbert Daniel, publicado em 1992, no ano em que Herbert Daniel faleceu. A contribuição para a luta contra a $A I D S$ foi tremenda.

\section{9 - Quais foram as principais dificuldades encontradas para realização deste livro?}

Houve três grandes desafios. Eu tinha pensado em escrever sua biografia depois que eu li seu livro de memórias, "Passagem para o próximo sonho", mas eu realmente não sabia como escrever uma biografia, e estava um pouco relutante em tentar. Então, estava apresentando um artigo em uma conferência sobre masculinidade revolucionária e esquerda brasileira quando Denise Rollemberg, uma historiadora da Universidade Federal Fluminense, sugeriu que eu contatasse sua mãe, D. Geny, que morava em Belo Horizonte. Ela escreveu um livro sobre exilados e conseguiu autorização para publicar algo em seu livro de Herbert Daniel através de D. Geny. Quando entrei em contato com D. Geny, ela imediatamente concordou com uma entrevista. Depois de três horas, eu sabia que tinha a base de um livro e, felizmente, ela me deu o nome do melhor amigo de Herbert quando eles estavam no ensino fundamental e médio. Depois de entrevistar Laís Pereira, percebi que conseguia encontrar material suficiente para escrever um livro.

Outro problema principal era entrevistar pessoas que não se lembravam de detalhes sobre o passado, ou porque haviam simplesmente esquecido depois de quarenta ou 
cinquenta anos ou porque na época em que estavam na clandestinidade foram treinadas para não saberem coisas que mais tarde poderiam prejudicar os outros se fossem presos e torturados. Então, há muitos buracos na história.

O problema final que enfrentei, foi que o manuscrito original era muito longo, e meu editor de língua inglesa insistiu que eu cortasse 45.000 palavras, o que no começo eu não queria fazer. Então meu parceiro disse: “Cortar, vai ser melhor.” E ele estava certo.

10- Seu livro contribui para os avanços das pautas identitárias da esquerda e sua relação com as lutas históricas dos direitos humanos. De que forma você acredita que a trajetória do Herbert Daniel pode contribuir para uma reflexão sobre a dispersão e articulação das lutas sociais?

Eu acredito que Herbert Daniel, especialmente em seus últimos anos como ativista político, concordaria comigo que diferentes movimentos identitários são extremamente importantes na mobilização de pessoas em favor de seus direitos democráticos específicos e, nesse processo, muitos deles entenderão que a discriminação e a opressão que eles vivem está ligada à dos outros.

Herbert entendeu que as pessoas têm muitas identidades e quando ele teve um contato inicial com o movimento LGBT, criticou o que ele pensava ser uma tendência para as pessoas afirmarem apenas uma identidade, a de ser um gay ou uma lésbica, e viver isolado da sociedade em que ele chamou um gueto. Anos mais tarde, quando descobriu que estava vivendo com $A I D S$, mudou radicalmente de posição e organizou pessoas para lidar com seu status sorológico, abraçá-lo e lutar contra aqueles que discriminavam pessoas vivendo com HIV/AIDS.

11 - O conceito de interseccionalidade tem sido utilizado por diversos pesquisadores para tratar da sobreposição ou articulação das diversas formas de hierarquização, opressão, dominação ou discriminação que incidem sobre os sujeitos sociais. Você argumenta que Herbert Daniel era sensível a pluralidade das lutas sociais. Como esta experiência pode nos ajudar a tratar teoricamente destes problemas nos fenômenos políticos atuais?

O conceito de interseccionalidade é útil ao enfatizar que as pessoas têm diferentes identidades e condições que afetam suas vidas de maneiras diferentes. Esta é uma maneira, eu acho que podemos falar sobre as ligações entre diferentes movimentos sociais ou políticos, pois os interesses das pessoas podem se sobrepor e se conectar. Assim, uma pessoa que é faz parte de uma família pobre e também gay pode entender que tanto a pobreza quanto a homofobia podem limitar suas possibilidades e, portanto, é necessário lutar contra ambas. O termo, creio eu, é outra maneira de falar sobre diferentes identidades e reconhecer que a sociedade pode atribuir valores hierárquicos, tanto positivos quanto negativos, a alguns sobre outros. Ele também pode fragmentar movimentos se articulado de uma maneira que não busque semelhanças entre as diferenças. 
12- As políticas identitárias tem sido uma demanda política relevante nas reivindicações dos movimentos sociais brasileiros. Como você discute a relação entre o debate sobre a universalidade dos direitos humanos e a particularidade das lutas por direitos LGBT+?

Pensando bem, existe uma dialética entre os dois. Eu vejo os direitos LGBT como direitos democráticos, que eu considero universalistas. Em essência, o movimento está lutando para que as pessoas possam ser quem são, o que não poderia ser um direito mais democrático que cada pessoa possa reivindicar. Nesse aspecto, é universalista.

13- Como é o trabalho de um historiador que ocupa-se com o resgate da memória, história e verdade a partir de arquivos da ditadura e de entrevistas com familiares de pessoas já falecidas? Como você lida com o conceito de "verdade" e o que seria resgatá-la? Como este trabalho pode contribuir para as pesquisas nos diversos campos das ciências sociais?

Eu não rejeito a noção de "verdade", apenas entendo que existem maneiras múltiplas de entender ou interpretar a realidade. Eu posso ver uma pintura abstrata em um museu por exemplo. Isso existe. Eu posso te dizer em qual museu eu vi. Eu posso conhecer o artista que fez a pintura. Estes são fatos ou verdades. No entanto, eu e a próxima pessoa que olha para a pintura podemos interpretá-la de maneiras inteiramente diferentes. Pode evocar sentimentos completamente diferentes em nós. Um de nós pode amá-lo; o outro odiá-lo.

Pesquisar e escrever sobre o passado é semelhante, e eu entendo que minha perspectiva pode ser completamente diferente da de outra pessoa, incluindo alguém que viveu naquele momento. Ao mesmo tempo, a questão de escrever sobre pessoas que não estão mais aqui e não têm voz é complicada. Não faço ideia se Daniel teria ou não gostado da minha biografia, se ele tivesse vivido para lê-la. Da mesma forma, não tenho certeza de que todas as pessoas que entrevistei estivessem inteiramente satisfeitas com seu retrato no livro ou com a captura da vida de Herbert Daniel.

Eu vou dizer, no entanto, que depois que eu dei a Dilma Rousseff uma cópia do manuscrito para ler, antes de entrevistá-la para o livro - ela foi a última pessoa que eu entrevistei - ficou tão satisfeita que quando me cumprimentou, confessou que estava preocupada em não gostar do livro, mas disse que estava com inveja do jeito que eu parecia capturar sua vida, pelo menos da sua perspectiva.

14-Do ponto de vista teórico e metodológico, como você aborda os aspectos subjetivos dos fenômenos políticos? Quais seriam as contribuições da psicologia social e da psicologia política para seu trabalho?

A participação na política é uma atividade muito subjetiva. Alguém poderia fazer a pergunta: por que uma pessoa se envolve na política revolucionária e arrisca sua vida por uma causa enquanto outra pessoa é inteiramente indiferente a essa questão? Quais são as razões pelas quais algumas pessoas querem se tornar líderes, enquanto outras insistem em ser seguidores? Quais são as dinâmicas de gênero das organizações políticas? Eu acho que há muitas questões que as pessoas envolvidas com a psicologia social poderiam perguntar sobre a oposição radical ao regime militar.

Da mesma forma, como é que algumas pessoas podem torturar os outros e depois voltar para casa com suas famílias? O que é sobre eles que lhes permite desligar suas emoções e tratar 
a outra pessoa de maneira tão desumana? E qual é a relação entre esse indivíduo e a instituição a que pertencem? Por que a ideologia anticomunista, por exemplo, convenceu algumas pessoas a fazerem coisas horrendas, como torturar alguém, o que outras pessoas teriam se recusado a fazer?

Acho que há muitas perguntas interessantes que poderiam ser feitas ao pesquisar sobre os momentos recentes da história do Brasil, especialmente quando alguém tem a oportunidade de entrevistar pessoas que viveram esses momentos.

15- Quais as principais diferenças que você percebe entre o Brasil e os EUA em relação a vivência da diversidade sexual e, consequentemente, sobre as frentes de lutas e os principais desafios para o avanço dos direitos LGBT?

A resposta a essa questão merece um longo livro, então só lhe darei uma resposta breve e superficial. Embora ambos os países tenham enfrentado o crescimento da direita política e especialmente os políticos cristãos evangélicos que fizeram das atividades anti-LGBT uma maneira de mobilizar e consolidar sua base de apoio ou os membros de suas igrejas, os contextos sócio-políticos dos dois países são totalmente diferentes.

Por exemplo, o movimento dos EUA cresceu significativamente em 1969 em meio às atividades políticas de esquerda - o movimento de guerra contra o Vietnã, o movimento de direitos civis, transformações culturais etc. Em um país relativamente democrático, com muitas instituições e tradições democráticas que permitiu que o movimento crescesse de maneira nacional e descentralizada em todo o país.

O movimento no Brasil surgiu durante um regime militar apenas cinco anos após a fundação do Somos: Grupo de Afirmação Homossexual, o primeiro grupo do país, a $A I D S$ e uma recessão que atingiu o país, imobilizando o movimento e dificultando a organização e o crescimento. O movimento foi muito pequeno e fraco durante a década de 1980, com poucos grupos, e só começou a crescer em tamanho e força na década de 1990 e no século XXI.

Outra grande diferença é que há uma longa tradição nos Estados Unidos de organizar pequenos grupos autogeridos independentes que não dependem de financiamento externo ou do governo para sobreviver. No Brasil, os ativistas vêm principalmente da classe média baixa, com poucos recursos financeiros para financiar grupos que dependem muito mais do Estado para sobreviver financeiramente.

Há uma população trans muito maior no Brasil em relação ao número de gays e lésbicas, e essa é outra grande diferença na natureza do movimento.

16 - Tivemos uma mudança significativa na atual conjuntura política brasileira, com o presidente eleito conquistando um número bem expressivo de votos no segundo turno das eleições, mesmo sustentando discursos excludentes e que ameaçam a cidadania de diversos setores da sociedade. Os votos alteraram também a configuração de poder no sistema de partidos, com partidos tradicionais cedendo espaço para setores fundamentalistas e conservadores, tanto na esfera federal como em diversos estados do Brasil. Qual a sua leitura dos resultados da última eleição?

Eu acompanho a situação de perto e é horrível. Mas o Brasil não está sozinho. As recentes eleições refletem uma tendência global de figuras autoritárias conservadoras, de extremadireita, que foram eleitas por meios democráticos, embora notícias falsas e novas estratégias de mídia social tenham influenciado indevidamente os resultados em muitos casos. As Filipinas, 
Rússia, Israel, Polônia, Hungria, Estados Unidos e Brasil são governadas por figuras autoritárias que usam o nacionalismo, o racismo e as ansiedades das classes médias para mobilizar o ódio e uma agenda social conservadora. A nostalgia de um passado inexistente e imaginário é combinada com uma agenda social moralista conservadora e com os argumentos de que as feministas, o movimento LGBT e a esquerda em geral destruíram a família, a moralidade e a sociedade como um todo. É um momento muito sério e perigoso para as pessoas LGBT + no Brasil e no mundo.

17 - Em seus escritos você argumenta que a ditadura atrasou em pelo menos uma década o surgimento do movimento homossexual brasileiro. Teremos algum impacto semelhante na atualidade?

Atualmente, o direito conservador e autoritário quer reverter todos os ganhos democráticos, sociais e econômicos alcançados nas últimas três décadas e mesmo antes da Assembleia Constituinte ter redigido uma nova constituição. Os movimentos LGBT, assim como todos os outros movimentos políticos e sociais, estarão na defensiva sob este novo governo, lutando para reter o que foi ganho e resistindo às forças do conservadorismo. Já existe um aumento na violência, pois a campanha eleitoral deu às pessoas homofóbicas a permissão para usar ameaças e violência para intimidar, prejudicar e até mesmo matar aqueles com quem eles discordam. Por outro lado, o movimento tem quarenta anos e milhões e milhões de pessoas LGBT aceitaram sua homossexualidade e conquistaram seus amigos, parentes e outros como aliados para apoiá-los. Será muito mais difícil voltar ao armário. As pessoas não querem. Eles gostam da liberdade que eles desfrutaram.

18 - O que James Green, pesquisador, diria para o Jimmy, ativista, sobre as estratégias e discursos necessários para organização da resistência nesse momento?

Eu estava nas primeiras dez Paradas do Orgulho Gay em São Paulo, em cada uma e em todas. Então parei de ir. Elas eram muito grandes, muitas pessoas, para muita confusão. No entanto, este ano estou planejando estar em São Paulo. Eu acho que será o maior desfile LGBT na história do mundo e um local de resistência. Eu acho que toda a esquerda estará lá para oferecer seu apoio e mostrar sua unidade com as pessoas LGBT e dizer NÃO às novas perspectivas políticas que estão assumindo. Será um enorme ato de resistência e um momento muito importante para encorajar outros movimentos sociais a reagir.

Nos Estados Unidos, antecipei a vitória eleitoral da direita em junho, pensando na época em que, se o candidato de Lula, que acabou sendo Haddad, vencesse, seria um governo fraco e precisaria de muito apoio. Por outro lado, se Alckmin ou Bolsonaro vencerem, os maus momentos virão. Então, comecei a planejar um encontro nacional, que realizamos em Nova York em $1^{\circ}$ de dezembro de 2018 na Columbia Law School para fundar a Rede dos EUA para a Democracia no Brasil. Atualmente, existem 35 grupos afiliados à rede nacional, alguns dos quais vêm se mobilizando desde o impeachment de Dilma Rousseff e outros que se formaram em resposta às recentes eleições. Temos contatos em 235 universidades em 45 estados e esperamos ter 100 grupos afiliados à Rede até o final do ano.

Nossa primeira grande campanha será organizar 100 eventos, protestos, ações, vigílias ou outras atividades em 14 de março, aniversário do assassinato de Marielle Franco, perguntando: quem a matou? Por que os assassinos não foram pegos e levados à justiça? Por que ela foi morta? 
Percebemos que a situação no Brasil não vai melhorar de um dia para o outro e por isso estamos nos preparando para o longo prazo.

19 - O que o Jimmy, ativista, diria para os pesquisadores sobre as pautas de pesquisa atuais? O que devemos considerar para avançarmos nas nossas pautas de pesquisa considerando o momento atual?

Como historiador, eu diria que é essencial que os estudiosos continuem visitando os arquivos, as bibliotecas e outros lugares para encontrar fontes e corrigir a história da homossexualidade no Brasil. Há muito mais a ser feito, tanto na escrita de histórias sociais - especialmente de lésbicas e trans, mas também de homens gays em cidades e vilas em todo o país. Ao mesmo tempo, é importante que as pessoas da antropologia e da sociologia sigam a resistência atual, estudem, aprendam com ela. Eu acho que a nova situação política vai criar muitas realidades diferentes, com as quais não estamos familiarizados e, assim, que temos que estudar e entender. Por exemplo, qual será o impacto da nova situação política para a saúde mental das pessoas LGBT+? Como os psicólogos sociais podem entender e responder à nova situação? Há muito a ser feito!

\section{Referências}

Green, J. (1999). Beyond Carnival: Male Homosexuality in Twentieth-Century Brazil. Chicago: University of Chicago Press.

Green, J. (2000). Além do Carnaval: a homossexualidade masculina no Brasil do século XX. São Paulo: UNESP.

Green, J. (2009). Apesar de vocês: a oposição à ditadura brasileira nos Estados Unidos, 1964-85. São Paulo: Companhia das Letras.

Green, J. (2010). We Cannot Remain Silent: Opposition to the Brazilian Military Dictatorship in the United States. Durham: Duke University Press.

Green, J. (2018). Exile within Exiles: Herbert Daniel, Gay Brazilian Revolutionary. Durham: Duke University Press.

Green, J. (2018). Revolucionário e gay: a extraordinária vida de Herbert Daniel - pioneiro na luta pela democracia, diversidade e inclusão (M. Sette Câmara, Trad., $1^{\text {a }}$ ed.). Rio de Janeiro: Civilização Brasileira.

Green, J. \& Polito, R. (2004). Frescos Trópicos: Fontes sobre a homossexualidade masculina no Brasil (1870-1980). Rio de Janeiro: Record.

Green, J. \& Quinalha, R. (Org.). (2014). Homossexualidade e a ditadura brasileira: Opressão, resistência e a busca da verdade (1 a ed.). São Carlos, SP: EdUFSCar.

Green, J., Quinalha, R., Caetano, M., \& Fernandes, M. (Org.). (2018). História do Movimento LGBT no Brasil. São Paulo: Alameda.

Green, J. \& Trinidad. R. (Org.). (2005). Homossexualismo em São Paulo e outros escritos. Com a participação de José Fábio Barbosa da Silva. São Paulo: Editora da UNESP. 


\section{ANDRÉA MOREIRA LIMA \\ https://orcid.org/0000-0002-3629-2856}

Mestre e Doutora em Psicologia pela UFMG, com estágio de doutoramento na Universidade de Coimbra/Portugal. Professora do Centro Universitário UNA.

Endereço: Cidade Universitária - Una Guajajaras

Rua dos Guajajaras, 175 - Centro, Belo Horizonte - MG, 30180-100

E-mail: andrea.m.lima10@gmail.com

\section{FREDERICO VIANA MACHADO}

https://orcid.org/0000-0002-8884-1124

Mestre e doutor em Psicologia pela UFMG. Professor do Bacharelado em Saúde Coletiva da Universidade Federal do Rio Grande do Sul, Porto Alegre, RS.

E-mail:phredvm@gmail.com

\section{Histórico}

Submissão: 21/02/2019

Revisão: 17/02/2020 